\title{
BUDAYA SEKOLAH UNGGUL
}

\author{
M..Chiar ${ }^{1}$
}

\begin{abstract}
Abstrak: Secara teoretik sebuah sekolah dapat manjadi baik, dapat dilihat dari dua dimensi organisasi. Pertama, dimensi "hard", berupa struktur organisasi, kebijakan, keuangan, sarana dan pra sarana sekolah dan sebagainya. Kedua, dimensi "soff", yaitu budaya organisasi yaitu terkait dengan the human side of organizational (aspek manusiawi dalam organisasi), meliputi nilai-nilai, keyakinan, budaya, serta norma-norma perilaku. Menurut para ahli manajemen pendidikan, dimensi yang kedua dipandang lebih berpengaruh terhadap keberhasilan sekolah.
\end{abstract}

Kata Kunci: Budaya organisasis, Sekolah unggul,

\section{Pendahuluan}

Budaya dalam konteks organisasi disebut dengan budaya organisasi (organizational culture). Dalam konteks perusahaan, diistilahkan dengan budaya perusahaan (corporate culture), dan pada lembaga pendidikan/sekolah disebut dengan budaya sekolah (school culture). Tentu saja berbeda dengan kajian budaya antropologi sosial atau organisasi perusahaan, dalam organisasi sekolah fokusnya pada perilaku, sehingga memunculkan kajian perilaku organisasi (organizational behavior).

Sebagaimana diketahui, dalam suatu organisasi di samping terdapat hal-hal yang bersifat hard juga ada yang sifatnya soft. Aspekaspek termasuk hard antara lain adalah: struktur organisasi, aturan-aturan, kebijakan, teknologi, dan keuangan. Hal- hal tersebut dapat diukur, dikuantifikasikan serta dikontrol dengan relatif mudah. Sedangkan hal-hal yang soft adalah yang terkait dengan the human side of organizational (aspek manusiawi dalam organisasi), meliputi nilai-nilai, keyakinan, budaya, serta norma-norma perilaku (Owens, 1995: 81).

Pada latar sekolah, budaya organisasi sebagai pola nilai-nilai, norma-norma, sikap, persepsi, pikiran-pikiran atau ide-ide, perilaku yang dibentuk dalam perjalanan panjang sekolah dan diyakini oleh warga

\footnotetext{
${ }^{1}$ M. Chiar adalah dosen Jurusan Ilmu Pendidikan FKIP-UNTAN Pontianak
} 
sekolah serta berfungsi sebagai suatu pedoman dalam memecahkan masalah-masalah di sekolah (Zamroni, 2003; Nasution, 1987). Karena dipengaruhi oleh visi dan misi serta tujuan, maka budaya sekolah bersifat unik. Walaupun sekolah itu sejenis, namun budayanya akan berbeda. Karena itu budaya sekolah disebut juga dengan sifat-sifat internal sekolah yang dapat membedakannya antara satu sekolah dengan lainnya.

Asumsi semula, kultur suatu bangsa diduga sebagai faktor penentu kualitas sekolah, namun berbagai penelitian menemukan bahwa pengaruh kultur bangsa terhadap prestasi pendidikan tidak sebesar yang diduga selama ini. Bukti terakhir dari hasil The Third International Math and Science Study (TIMSS) menunjukkan bahwa siswa dari Jepang dan Belgia sama-sama menempati ranking atas untuk mata pelajaran Matematika, padahal kultur kedua negara tersebut berbeda. Saatnyalah sekarang pengelola pendidikan lebih memfokuskan kultur sekolah sebagai faktor penentu prestasi sekolah.

\section{Budaya Orgaisasi Sekolah}

Setiap organisasi mempunyai suatu budaya yang dapat berpengaruh pada sikap dan perilaku anggota-anggotanya, tidak terkecuali pada organisasi pendidikan/sekolah. Seiring dengan perkembangan ilmu perilaku organisasi (organizational behavior), maka pengertian budaya organisasi mengalami perkembangan dan penyempurnaan. Gibson, Ivancevich dan Donnelly (1996: 77) mengartikan budaya organisasi sebagai perpaduan nilai-nilai, kepercayaan, asumsi, persepsi, norma, kekhasan dan pola perilaku dalam suatu orgaisasi. Dalam aktivitas organisasi terdapat pola-pola mengenai nilai-nilai, asumsi, kepercayaan, sikap-sikap, harapan-harapan dan norma-norma yang telah berkembang sejak lama dapat menciptakan pemahaman yang sama diantara para anggota dan memberikan arah dalam berperilaku. Sementara Luthans (1989: 76) mengemukakan sebagai berikut: Organizational culture as a pattern of basic assumptions-invented, discovered, or developed by a given group as it learns to cope with its problems of external adaptation and internal integration-that has worked well enough to be considered valuable and, therefore, to be taught to new members as the correct way to perceive, think, and feel in relation to those problems. Definisi dimaksud menjelaskan bahwa budaya organisasi sebagai pola dasar dalam mengembangkan kelompok untuk belajar mengatasi persoalan penyesuaian internal dan eksternal dan diajarkan kepada anggota-anggota baru sebagai cara yang benar dalam memahami, berfikir dan merasakan permasalahan yang dihadapi. 
Permasalahan dapat bersumber dari dalam organisasi, namun tidak jarang ber-asal dari luar organisasi. Sebagaimana dikemukakan oleh Kreitner dan Kinicki (2003), lingkungan eksternal besar pengaruhnya terhadap budaya organisasi, namun anggota kelompok merasakan, memikirkan dan bereaksi terhadap lingkungan yang beraneka ragam. Sedangkan budaya organisasi merupakan suatu sistem makna bersama yang memberikan arah pada perilaku anggotanya yang membedakan satu organisasi dengan organisasi lainnya (Robbins dan Coulter, 1999). Definisi budaya organisasi di atas mengandung arti bahwa budaya organisasi terwujud dalam filosofi, nilai-nilai, keyakinan serta sikap dan norma bersama anggota-anggota organisasi tersebut dalam memandang berbagai realitas terutama dalam mengatasi permasalahan internal dan eksternal.

Persoalan internal dan eksternal tidak hanya dialami oleh perusahaan swasta, tetapi juga terjadi pada organisasi pendidikan. Budaya organisasi sekolah (The organizational culture school) dapat dideskripsikan sebagai pola nilai-nilai, norma-norma, sikap, persepsi, pikiran-pikiran, ide-ide, atau perilaku yang dibentuk dalam perjalanan panjang sekolah dan diyakini oleh warga sekolah serta berfungsi sebagai suatu pedoman dalam memecahkan masalah-masalah di sekolah (Zamroni, 2003: 149).

Budaya organisasi juga dapat dilihat sebagai suatu perilaku, nilainilai, sikap hidup, dan cara untuk melakukan penyesuaian dengan lingkungan dan sekaligus cara untuk memandang persoalan dan strategi pemecahannya. Karena itu, secara alami kebudayaan akan diwariskan oleh satu generasi kepada generasi berikutnya. Sedangkan sekolah merupakan lembaga utama yang dirancang untuk memperlancar proses transmisi antar generasi. Karena itu budaya sekolah harus dapat menjadi rujukan warga sekolah (kepala sekolah, guru, siswa) dalam menghadapi tantangan untuk menjadi sekolah modern, sebagaimana dikemukakan oleh Murgatroyd dan Morgan (1994: 373) sebagai berikut: "The organizational culture school challenges the basic views of the 'modern'structural and systems schools about for example, how organizations make decisions, and how and why people in organizations behave as they do". Kultur organisasi sekolah harus dapat membangun sistem yang memungkinkan organisasi mampu mengambil keputusan, dan anggota-anggota organisasi bertindak sesuai dengan harapan-harapan yang diyakini bersama.

Sergiovanni (1991:109) menyimpulkan bahwa kultur sekolah (The culture of the school) merupakan hasil konflik dan rumusan negoisasi, dan berpengaruh pada bahasa sekolah, kiasan, dongeng dan 
upacara keagamaan sebagaimana dikemukakannya berikut: "The culture of the school is therefore the product of conflict and negotiation over definitions of situations, . . . influence on school language, metaphor, myths and ritual is a major factor in the determination of the culture which is reproduced in the consciousness of teacher and pupils. Secara lebih singkat, Nasution (1993: 72) mengemukakan bahwa budaya sekolah adalah pola kelakuan, norma-norma yang ber-langsung dalam kehidupan sekolah dan yang diharapkan masyarakat.

Dengan demikian budaya organisasi sekolah adalah nilai-nilai, kepercayaan, asumsi, harapan dan norma-norma, pikiran-pikiran atau ideide yang dibentuk dalam perjalanan panjang sekolah dan diyakini sebagai pedoman dalam berperilaku bagi warga sekolah terutama dalam memecahkan masalah internal dan eksternal sekolah.

Budaya sekolah yang dikembangkan sebaiknya disesuaikan dengan budaya setempat, sehingga tidak menimbulkan benturan tata nilai, norma, serta kaidah-kaidah yang telah diyakini warga sekolah. Dalam buku Manajemen Peningkatan Mutu Berbasis Sekolah pada buku 4 yang membahas tentang Pedoman Tatakrama dan Tata Tertib Kehidupan Sosial Sekolah Tahun 2001 dijelaskan bahwa, "Sebagai acuan dasar, tatakrama dan tata tertib kehidupan sosial sekolah hendaknya bersumber pada nilainilai agama (akhlak mulia), nilai sosial budaya setempat, tetapi tetap dalam kerangka pengembangan budaya nasional". Lebih lanjut dijelaskan dalam buku dimaksud, bahwa mengingat sifatnya yang mencerminkan kebutuhan masing-masing sekolah dalam kontek masyarakat lokal, maka tatakrama dan tata kehidupan sosial sekolah merupakan bagian yang tidak terpisahkan dari program manajemen peningkatan mutu berbasis sekolah (school-based quality improvement) sebagai salah satu manajemen pendidikan. Karena itu setiap daerah mempunyai ciri khas budaya yang diyakini sebagai pedoman dalam berperilaku terutama dalam memecahkan masalah-masalah di sekolah.

\section{Terbentuknya Budaya Organisasi Sekolah}

Suatu organisasi berkembang dan membentuk pola budaya tertentu sesuai dengan falsafah yang di anut dan tujuan yang hendak dicapai. Dikemukakan oleh Siswohartono (1992) bahwa, walaupun organisasi itu sejenis, namun budayanya akan berbeda. Karena itu budaya organisasi disebut juga sifat-sifat internal organisasi yang dapat membedakannya dengan organisasi lain. Selain itu, terbentuknya budaya organisasi melalui proses panjang, dan pada awalnya merupakan sebuah filosofi pendiri organisasi. 
Membangun budaya sekolah (School culture building) merupakan seni dan kreativitas pimpinan institusi, sebagaimana dikemukakan oleh Sergiovanni (1991: 109) berikut:

The art of the creative leader is the art institution building, the rework-ing of human and technological materials to fashion an organism that embodies new and enduring values. To institutionalize is to infuse with value beyond the technical requirements of the task at hand. The prizing of social machinery beyond its technical role is largely a reflection of the unique way it fulfills personal or group needs. Whenever individuals become attached to an organization or a way of doing things as persons rather than as technicians, the result is a prizing of the organization is changed from an expenda-ble tool into a valued source of personal satisfaction.

Kreativitas pemimpin dibutuhkan dalam membentuk budaya organisasi, terutama membangun nilai-nilai baru yang dapat memberikan arah perkembangan organisasi dan dijadikan rujukan bagi semua anggota. Perkembangan organisasi diharapkan dapat mengarah pada pemenuhan kebutuhan individu anggota, kelompok-kelompok kerja sehingga dapat memberikan kepuasan pribadi (personal satisfaction).

Sebagaimana dijelaskan di muka bahwa, budaya organisasi terbentuk melalui proses dan tahapan tertentu. Dikemukakan oleh Hodge dan Anthony (1988), terdapat empat tahapan pembentukan budaya organisasi, yaitu: (1) dependency/authorityc con-frontation (ketergantungan/konfrontasi otoritas); (2) confrontation of intimacy, role differentiation, peer relationship issues (konfrontasi keakraban, pembedaan peran, dan isu-isu hubungan antar sejawat); (3) creativity/stability(kreatifitas/stabilitas); dan (4) survival/growth issues (isu pertumbuhan/dapat bertahan).

Pada tahap pertama peran pemimpin sangat menentukan. Karena itu kelompok biasanya menentukan kriteria kepemimpinan yang dapat mereka terima, apakah berdasarkan pengalaman, kecakapan, kewibawaan, atau keturunan. Pemimpin yang pertama biasanya memberikan pengaruh besar terhadap budaya organisasi. Keyakinan-keyakinan dan nilai-nilai yang diletakkan oleh pendiri (founder) akan dijadikan acu-an para pengikutnya.

Tahap kedua ditandai dengan isu-isu seputar pertentangan antara kedekatan, perbedaan peran dan hubungan antara teman sejawat. Keberhasilan yang dicapai pada tahap pertama mendatangkan perasaan berhasil dan hubungan baik di antara anggota. Hal ini disusul dengan 
tahap ketiga, yaitu kelompok mulai dihadapkan pada pertentangan antara semangat inovasi dan kreativitas dengan kecenderungan terhadap kemapanan. Di sini sering terjadi konflik peranan yang disebabkan oleh ketidakcocokan antara dimensi institusional dengan dimensi individual.

Pada tahap berikutnya kelompok akan mencapai kematangan ketika dihadapkan pada tuntutan untuk survive dan pertumbuhan. Dalam tahap ini organisasi mulai cenderung pada status quo dan menolak perubahan.

Robbins (2003: 321) menjelaskan proses terbentuknya budaya organisasi sebagai berikut, Pada mulanya budaya organisasi terbentuk dari filosofi pendiri organisasi. Selanjutnya budaya tersebut digunakan sebagai kriteria dalam merekrut dan menyeleksi karyawan yang akan bergabung dalam organisasi. Tindakan manajemen puncak menentukan kriteria perilaku yang baik dan dapat diterima sedangkan yang tidak baik ditolak. Proses sosialisasi nilai-nilai organisasi terhadap karyawan baru bergantung pada tingkat keberhasilan yang dicapai melalui proses seleksi maupun preferensi ma-najemen puncak dalam menyosialisasikan nilainilai organisasi. Proses terbentuknya budaya organisasi dilukiskan dalam bentuk gambar sebagai beerikut:

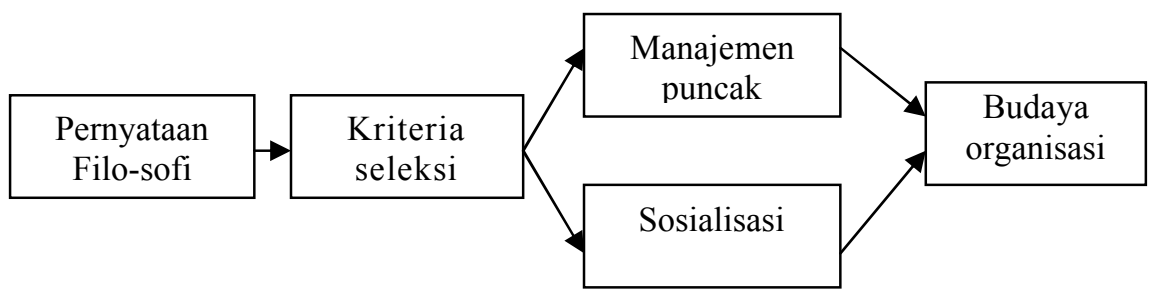

Gambar 2.1 Terbentuknya Budaya Organisasi (Robbin, 2003: 322)

Dalam konteks organisasi sekolah, pimpinan puncak adalah kepala sekolah yang mempunyai peran penting dalam mengarahkan sekolah. Preedy (1993) menyatakan "traditionally the culture in schools was one of high concensus, often cantred on strong loyalty to a haerdreacer who was expected to symbolize and expound the culture of the school, rather like a monarch". Artinya secara tradisional budaya sekolah merupakan suatu konsensus tingkat tinggi, seringkali didasarkan pada loyalitas yang kuat kepada kepala sekolah yang lebih diharapkan untuk memberikan simbol/dan menampilkan budaya sekolah, dari pada bertindak sebagai penguasa. 
Proses pembentukan budaya organisasi terjadi pada setiap organisasi tanpa terkecuali pada organisasi sekolah. Pada organisasi sekolah, peranan kepala sekolah sangat menentukan dalam pengembangan akademik dan peningkatan prestasi sekolah. Zamroni (2003: 150) menjelaskan bahwa, nilai, moral, sikap dan perilaku siswa berkembang selama waktu di sekolah, dan perkembangannya dipengaruhi oleh struktur dan budaya sekolah, serta oleh interaksi dengan komponen-komponen yang ada di sekolah, seperti kepala sekolah, guru, materi pelajaran dan antar siswa sendiri. Hal senada dikemukakan oleh Thomas (1989) sebagai berikut: "principals can take many concrete steps to aid the development of an academic orientation and high achievement expectations, virtually all of which reflect their instructional leadership role". Kepala sekolah dapat mengambil langkah-langkah konkrit untuk membantu pengembangan akademik dan harapan terhadap prestasi tinggi yang mencerminkan peran kepemimpinan. Pengembangan akademik dan prestasi sekolah dapat dicapai apabila tercipta budaya sekolah yang kondusif dalam arti seluruh anggota sekolah (Kepala sekolah, guru, siswa) mempunyai komitmen terhadap nilai-nilai, kepercayaan, asum-si, harapan dan norma-norma serta aturan tertulis termasuk program kerja yang dapat dijadikan landasan bagi pelaksanaan tugas di sekolah.

\section{Ragam Nilai dalam Budaya Sekolah Unggul}

Secara bahasa "keunggulan" berarti keadaan (lebih) unggul, keutamaan; kepandaian (kecakapan, kebaikan, kekuatan, dan sebagainya) lebih dari yang lain (Depdikbud, 2005). Dari pengertian tersebut, hakikat nilai keunggulan terletak pada adanya pembanding antara satu hal (kinerja, kemampuan, prestasi atau benda) yang satu lebih bernilai dari yang lain. Perbandingan dimaksud antara prestasi (kemampuan) seorang siswa dengan siswa lain, sekelompok siswa dengan kelompok yang lain, seorang/kelompok guru dengan guru yang lain, atau satu sekolah dengan sekolah lain.

Nilai keunggulan (excellence) ini termuat dalam dua bentuk yaitu, perilaku dan raga (fisik). Perilaku yang memuat nilai keunggulan adalah perilaku yang secara komparatif lebih baik (etis) serta lebih berhasil guna (utility) dibanding perilaku yang lain. Perilaku dimaksud dapat ditunjukkan dalam penguasaan berbagai hal (pengetahuan dan keterampilan). Pada bentuk fisik, nilai keunggulan termuat dalam benda yang lebih indah (estetis) atau lebih berguna dibanding yang lain. Dari segi statusnya, nilai keunggulan dapat dikategorikan sebagai nilai terminal (unggul itu sendiri memiliki nilai), sekaligus nilai instrumental (melalui 
keunggulan dapat dicapai hal-hal lain, seperti kebanggaan, hadiah, popularitas dan sebagainya.

Studi-studi tentang budaya sekolah yang di lansir oleh Zamroni (2003) menemukan bahwa kultur yang "sehat" memiliki korelasi yang tinggi terhadap (a) prestasi dan motivasi siswa untuk berprestasi, (b) sikap dan motivasi kerja guru, dan (c) produktivitas dan kepuasan kerja guru. Analisis kultur sekolah sebaiknya dilihat sebagai bagian suatu kesatuan sekolah yang utuh. Artinya, budaya sekolah dapat dijelaskan melalui pola nilai-nilai, sikap, pikiran-pikiran, dan perilaku warga sekolah yang tercermin pada (a) motivasi berprestasi, (b) penghargaan yang tinggi terhadap prestasi warga sekolah, (c) pemahaman terhadap tujuan sekolah, (d) visi organisasi yang kuat, (e) partisipasi orang tua siswa, (f) kerjasama yang padu diantara guru.

Demikian pula studi yang dilakukan Hariyadi (2004) terhadap tiga sekolah unggul di Salatiga menemukan ciri-ciri sekolah unggul sebagai berikut; (a) nilai prestasi dan persaingan, (b) nilai keefektifan, (c) kedisiplinan, (d) kemandirian, (e) prestise (kebanggaan).

Prestasi dan persaingan merupakan dua nilai terpisah, namun keduanya dapat dipasangkan. Prestasi diukur dengan standar pencapaian, sedangkan persaingan diukur dengan membandingkan prestasi seorang anak dengan anak lain, atau satu sekolah dengan sekolah lain. Keefektifan terwujud dalam pelaksanaan kerja, baik siswa, guru maupun sekolah secara institusional. Keefektifan sekolah juga ditandai oleh kepemimpinan pengajaran yang kuat, fokus hasil belajar yang jelas, ekspektasi yang tinggi terhadap siswa, lingkungan yang nyaman dan teratur. Kedisiplinan, esensi nilai kedisiplinan terkait dengan ketepatan waktu dan kepatuhan terhadap tata tertib atau peraturan. Kemandirian, merupakan kemampuan serta keberanian mengambil keputusan dan siap menanggung risiko atas keputusannya. Dalam kehidupan individu atau kelompok, kemandirian tidak berarti isolasi, eksklusifisme, akan tetapi sebaliknya ia bercirikan keterbukaan, interdependensi, kepedulian, kerjasama dan harga diri. Prestise, nilai ini yang melekat dengan status, yaitu status sekolah yang memiliki reputasi, gengsi, dan nama baik. Siswa, orang tua, maupun guru menjadi bagian dari sekolah tersebut, maka dalam diri mereka juga merasa bangga terhadap reputasi sekolah.

Secara singkat, nilai utama yang memberikan sumbangan terbesar bagi budaya sekolah adalah nilai keunggulan. Nilai keunggulan telah meresap atau tercermin dalam citra diri (self image) seluruh warga sekolah, terutama para siswa dan guru. Dengan memiliki citra diri, mereka 
memiliki motivasi kerja yang tinggi untuk mempertahankan keunggulan yang diraih.

\section{DAFTAR PUSTAKA}

Depdiknas. (2001) Manajemen Peningkatan Mutu Berbasis Sekolah: Pedoman Tatakrama dan Tata Tertib Kehidupan Sosial Sekolah bagi SLTP. Jakarta: Depdiknas- Dirjen Dikdasmen

Gibson, J.L., Invancevich, J.M. dan Donnelly, Jr. J.H. (1996). Organisasi: Perilaku,

Struktur dan proses. (edisi kedelapan), Alih Bahasa: Nunuk Ardiani, Jakarta:

Binarupa Aksara.

Hodge, B.J., \& Anthony, W.P. (1988). Organizational Theory. ( $3^{\text {rd }}$. Ed.). Boston, Massa-chusetts: Allyn and Bacon Inc.

Kreitner, R. \& Kinicki, A. (2003). Organizational Behavior. Boston: The McGraw-Hill Companies, Inc.

Luthans, F. (1989). Organizational Behavior. New York: McGraw-Hill Book Com-pany.

Murgatroyd, S. \& Morgan, C. (1994). Total Quality Management and School. Philadelphia: Open University Press.

Nasution, S. (1987). Sosiologi Pendidikan. Bandung: Jemmars

Owens, R.G. (1995). Organization Behavior in Education. Second Edition. Boston: Allyn and Bacon.

Robbins, S.P. dan Coulter, M. (1999). Manajement. Sixth Editions. Englewood Cliffs: Prentice Hall, Inc.

Robbins, S.P. (2003). Perilaku Organisasi: Konsep, Kontroversi, dan Aplikasi. Alih Bahasa Oleh Pujaatmaka Hadyana. Jakarta : PT. Prenhallindo. 
Sergiovanni, T.J. (1991). The Principalship A Reflective Practice Perspective. ( $2^{\text {nd }}$ Edition). Massachusetts: A Division of Simon \& Schuster, Inc.

Siswohartono, J. (1992). Studi tentang Kultur Organisasi Universitas Harapan Ne-gara. Disertasi tidak Dipublikasikan. Malang: PPS Universitas Negeri Malang.

Thomas, R. M. (1989). Schooling in East Asia. Oxford: Pergamon Press.

Zamroni. (2003). Paradigma Pendidikan Masa depan. Jakarta: Bigraf Publishing. 